Delft University of Technology

\title{
An Experimental Study of Foam Trapping and Foam Mobility in a Model Fracture
}

Li, K.; Wolf, K.H.A.A.; Rossen, W.R.

DOI

10.3997/2214-4609.202133018

Publication date

2021

Document Version

Final published version

Published in

IOR 2021 - 21st European Symposium on Improved Oil Recovery

\section{Citation (APA)}

Li, K., Wolf, K. H. A. A., \& Rossen, W. R. (2021). An Experimental Study of Foam Trapping and Foam Mobility in a Model Fracture. In IOR 2021 - 21st European Symposium on Improved Oil Recovery: 21st European Symposium on Improved Oil Recovery, 19-22 April 2021, Online Event (pp. 1-10). EAGE. https://doi.org/10.3997/2214-4609.202133018

Important note

To cite this publication, please use the final published version (if applicable).

Please check the document version above.

\section{Copyright}

Other than for strictly personal use, it is not permitted to download, forward or distribute the text or part of it, without the consent of the author(s) and/or copyright holder(s), unless the work is under an open content license such as Creative Commons.

Takedown policy

Please contact us and provide details if you believe this document breaches copyrights.

We will remove access to the work immediately and investigate your claim. 
Green Open Access added to TU Delft Institutional Repository

'You share, we take care!' - Taverne project

https://www.openaccess.nl/en/you-share-we-take-care

Otherwise as indicated in the copyright section: the publisher is the copyright holder of this work and the author uses the Dutch legislation to make this work public. 


\title{
18
}

\section{An Experimental Study of Foam Trapping and Foam Mobility in a Model Fracture}

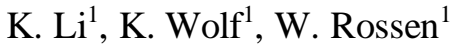 \\ ${ }^{1}$ Technology University of Delft
}

\section{Summary}

By trapping gas, foam can improve the sweep efficiency in enhanced oil recovery. In this study, to understand gas trapping in fractures, we have conducted experiments in a model fracture with a hydraulic aperture of $80 \mu \mathrm{m}$. One wall of the fracture is rough, and the other wall is smooth. The fracture is made of two glass plates and the direct visualization of foam flow inside the fracture is facilitated using a high-speed camera. ImageJ has been used to perform image analysis and quantify the properties of the foam. We find that pre-generated foam has been further refined inside the model. Foam flow reaches local equilibrium, where the rate of bubble generation equals that of bubble destruction, within the model. Foam texture becomes finer and less gas is trapped as the interstitial velocity and pressure gradient increase. Shear-thinning rheology of foam has also been observed. The behavior of gas trapping in our model fracture is different from that in other geological porous media. The fraction of trapped gas is much lower (less than 7\%). At the extreme, when velocity increases to $6.8 \mathrm{~mm} / \mathrm{s}$ (pressure gradient to 1.8 $\mathrm{bar} / \mathrm{m}$ ), all the foam bubbles are flowing and there is no gas trapped inside the fracture. 


\begin{abstract}
By trapping gas, foam can improve the sweep efficiency in enhanced oil recovery. In this study, to understand gas trapping in fractures, we have conducted experiments in a model fracture with a hydraulic aperture of $80 \mu \mathrm{m}$. One wall of the fracture is rough, and the other wall is smooth. The fracture is made of two glass plates and the direct visualization of foam flow inside the fracture is facilitated using a high-speed camera. ImageJ has been used to perform image analysis and quantify the properties of the foam. We find that pre-generated foam has been further refined inside the model. Foam flow reaches local equilibrium, where the rate of bubble generation equals that of bubble destruction, within the model. Foam texture becomes finer and less gas is trapped as the interstitial velocity and pressure gradient increase. Shear-thinning rheology of foam has also been observed. The behavior of gas trapping in our model fracture is different from that in other geological porous media. The fraction of trapped gas is much lower (less than 7\%). At the extreme, when velocity increases to $6.8 \mathrm{~mm} / \mathrm{s}$ (pressure gradient to $1.8 \mathrm{bar} / \mathrm{m}$ ), all the foam bubbles are flowing and there is no gas trapped inside the fracture.
\end{abstract}

\title{
Introduction
}

As a promising means of enhanced oil recovery (EOR), gas injection has a good displacement efficiency at the level of the pore (Lake et al. 2014). Under some conditions, gas can displace all oil where it floods. However, the sweep efficiency of gas injection is usually low, due to conformance problems including gravity segregation, viscous fingering and channelling. Conformance problems exist because gas has a lower density and lower viscosity compared to in-situ fluids (Kim et al. 2005), and the reservoir is heterogeneous. As a result, the front of the displacing gas is unstable, which leads to a poor sweep. In naturally fractured reservoirs, heterogeneity is more complicated and conformance problems are worse. Gas can flow easily in highly permeable fractures, leading to a quick breakthrough of gas, and much oil in the matrix is bypassed. As a result, the sweep efficiency of gas injection in naturally fractured reservoirs is even lower.

Foam can mitigate conformance problems associated with gas injection. Foam is composed of separated gas bubbles separated by liquid films. The films, called lamellae, are stabilized by surfactants. In foam, gas disconnects, and liquid is the continuous phase. Successful foam application has been reported in many areas, including acid diversion (Thompson and Gdanski 1993), aquifer remediation (Hirasaki et al. 1997; Portois et al. 2018), and gas flooding in EOR (Kovscek and Radke 1994; Rossen 1996). The application of foam in EOR has been studied for decades, both theoretically and experimentally. It has been found that foam can reduce the mobility of gas and improve sweep efficiency, hence increasing recovery. The main mechanism of gas mobility reduction is gas trapping. During foam injection, much gas occupies the pore space, because viscous force is not large enough to mobilize them. These gas bubbles are trapped in-situ and limit channels where foam can flow. As a result, the relative permeability of gas decreases, and the mobility of gas is greatly reduced, often by a factor of hundreds or more (Tang and Kovscek 2006). In fractures, foam can also be generated and propagates (Kovscek et al. 1995; Fern $\varnothing$ et al. 2016; AlQuaimi and Rossen 2019). The pressure gradient built up by foam in fractures can divert gas into the matrix. Therefore the sweep efficiency is improved.

The extent of gas trapping determines the ability of the foam to reduce gas relative permeability and thereby reduce the mobility of gas. Thus, it is crucial to understand the mechanism of gas trapping for a successful foam application in the field. Previous experimental studies (Radke and Gillis 1990; Friedmann et al. 1991) were performed to investigate gas trapping in cores, using a 1-D model for tracer transport to match the profile of a gas tracer in the effluent. It has been concluded that above $80 \%$ and nearly $100 \%$ of the gas are trapped. Nguyen et al. (2009) used the X-ray computed tomography method to recreate the effluent tracer concentration to improve the estimation of the trapped-gas fraction. They found that, with an increasing gas velocity, the trapped-gas fraction decreases. However, with a decreasing liquid velocity, it increases. More recently, using a more advanced mass-transfer model, Kil et al. (2011) analyzed the CT images and measured the trapped-gas fraction to be $99 \%$. 
In recent years, in the research field of foam EOR, the microfluidic system (a network of channels with widths from tens to hundreds of microns) has become more and more useful. Its transparency allows foam flow experiments to be directly observed at the pore scale (Marchalot et al. 2008; Conn 2015). In a microfluidic model, Jones et al. (2018) studied gas trapping and reported a strong response of trappedgas fraction to velocity. As velocity dropped from 400 to $50 \mathrm{~mm} / \mathrm{s}$, the fraction of trapped gas increased from $12 \%$ to $63 \%$. They showed that bubbles are more likely to coarsen to pore size within the model at lower speeds and then more effectively block individual pores and increase the fraction of trapped gas.

In this study, to examine gas trapping behavior and how it affects foam mobility in fractures, we carry out experiments on a 1-meter-long, 15-centimeter-wide model. The model fracture is made of two glass plates and has one rough and one smooth wall (AlQuaimi and Rossen 2019). The transparency of the glass model fracture allows us to visualize foam flow processes during experiments. A high-speed camera tracks the flow of foam. Using the ImageJ software package, bubble texture of foam and fractions of trapped gas are quantified. In this paper, we first explain our experimental setup and research methodologies. Then we show how foam develops along the fracture. Gas trapping behavior at our flow conditions is reported. How gas trapping affects foam mobility is also discussed. At the end of this paper, conclusions are drawn.

\section{Experimental Setup and Materials}

The experimental apparatus for foam tests is shown in Figure 1. The surfactant solution is injected by a dual-cylinder non-pulse pump (VINDUM Engineering, INC.) and gas injection is controlled by a massflow controller (Bronkhorst Nederland B.V.). Seven absolute pressure detectors (DEMO MPXH6400A, range 4 bar) are used to measure the pressure along the model fracture at various locations. The volumetric injection rates of the surfactant solution and gas are managed by a computer. The computer also handles the data acquisition from the pressure transducers.

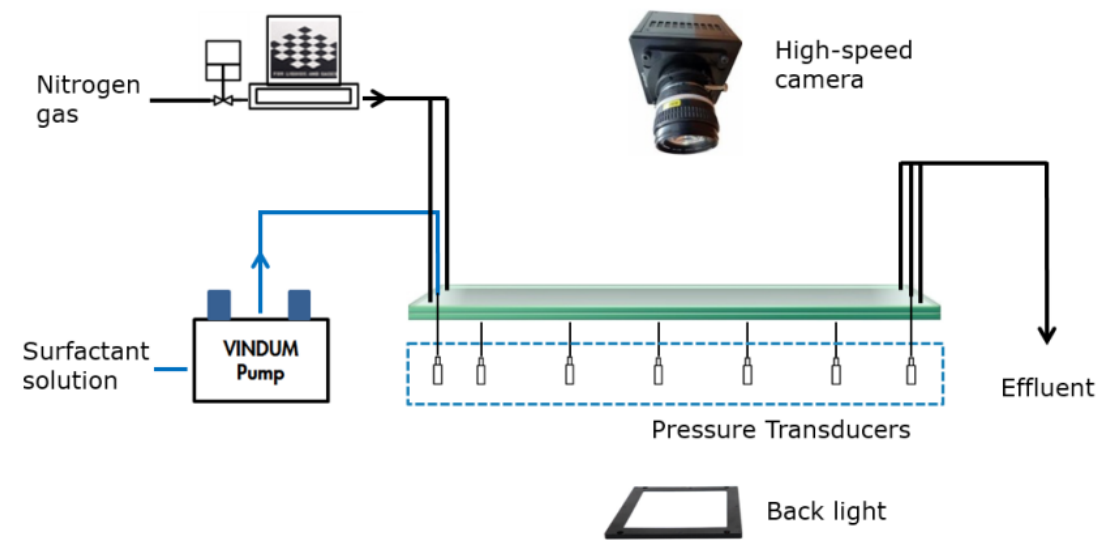

Figure 1 Experimental setup

The fracture model is $1 \mathrm{~m}$ long and $15 \mathrm{~cm}$ wide and consists of two glass plates (Hijman Glas B.V., the Netherlands). One plate is smooth and the other one is rough on the side facing the other plate. Both plates are $2 \mathrm{~cm}$ thick. To create the model fracture, the two glass plates are mounted directly against each other and sealed along four edges with Silicon rubber (ResinTechnology B.V.). The model is then mounted in an aluminium clamping frame (Fig. 2). The fracture aperture is defined by the gap between the two plates. Eleven holes were drilled along the length of the fracture through the roughened plate for the injection and production of foam and connection to the pressure detectors. Pressure differences were measured across six sections. 


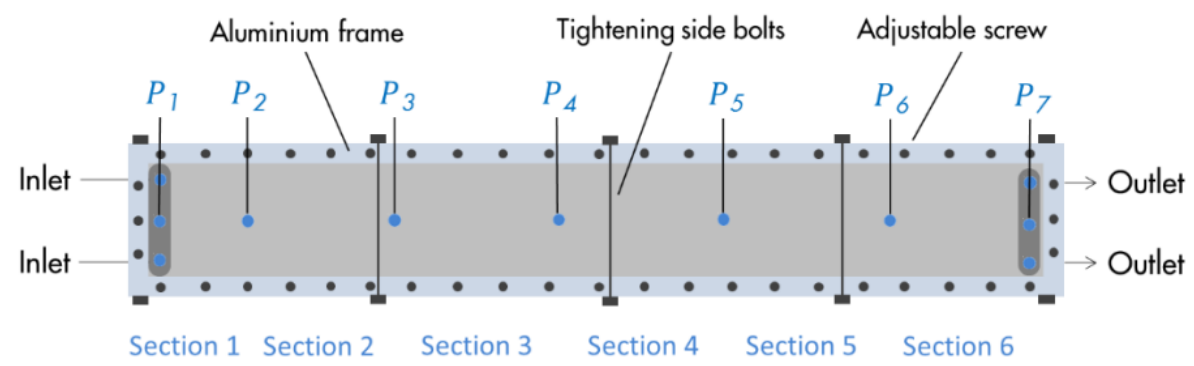

Figure 2 The model fracture and the aluminium clamping frame

As shown in Figure 1, a high-speed camera (Photron Fastcam UX50) mounted above the fracture is used to take images of foam within the fracture during experiments. A computer controls the camera program and manages the image acquisition. A high-parallelism back-light system (VAL LED illumination) is used to provide light for the camera. To prevent external reflections, the setup is installed in a tent.

In this study, 1 wt \% AOS C14-16 (Stepan® BIO-TERGE AS-40 KSB) surfactant solution is used as the liquid phase of the foam, and nitrogen (Linde Gas Benelux B.V.) is used as the gas phase.

\section{Theories and Methodologies}

The hydraulic aperture $d_{H}$ of the model fracture is determined before performing any foam experiment. We estimate $d_{H}$ by injecting demineralized water through the model at gradually increasing rates. A regression of pressure gradient against flow rate determines $d_{H}$ (Witherspoon et al. 1980):

$$
\left|\nabla P_{w}\right|=12 q_{w} \frac{1}{w d_{H}^{3}} \mu_{w}
$$

where $\nabla P_{w}$ is the pressure gradient, $q_{w}$ is the water volumetric injection rate, $w$ is the width of the model, and $\mu_{w}$ is water viscosity. The value of $d_{H}$ obtained from Eq. 1 is $80 \mu \mathrm{m}$ for our model.

Foam is pre-generated through a mixing tee (Upchurch Scientific IDEX Health \& Science LLC, PEEK, $10 \mu \mathrm{m}$ ) at foam quality $f_{g}$ (ratio of gas volumetric rate to total rate) of 0.9 and at varying total interstitial velocities $v_{t}$ from 0.12 to $6.79 \mathrm{~mm} / \mathrm{s}$. Then foam flows through the model fracture. The fracture is placed horizontally and all tests are conducted at room temperature and ambient pressure.

To quantify the mobility of steady-state foam, the time-averaged pressure data are used to calculate the apparent viscosity of foam, $\mu_{\text {app }}$.

$$
\mu_{\text {app }}=\frac{1}{12} \frac{1}{q_{t}}\left|\nabla P_{\text {foam }}\right| w d_{H}^{3}
$$

where $q_{t}$ is the total volumetric flow rate, and $\nabla P_{\text {foam }}$ is pressure gradient of foam.

Images are taken during steady-state foam flow to study gas trapping and bubble texture in the foam. ImageJ software is used to process and analyze images of foam. The number of bubbles per unit area (bubble density) and the distribution of the bubble sizes are then measured. The fraction of gas trapping (ratio of the trapped-gas area over the total-gas area) can also be estimated using image analysis. 


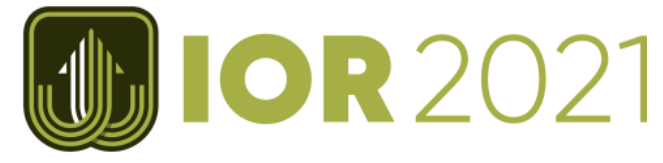

\section{Foam Evolution and Local Equilibrium}

Foam is first pre-generated via the mixing tee, and then injected into the fracture. Once the steady state is reached, the pressure data is used to compute the apparent viscosity of foam. Figure 3 shows the apparent viscosity of foam in different sections of the fracture at various velocities (in this apparatus, interstitial and superficial velocities are equal).

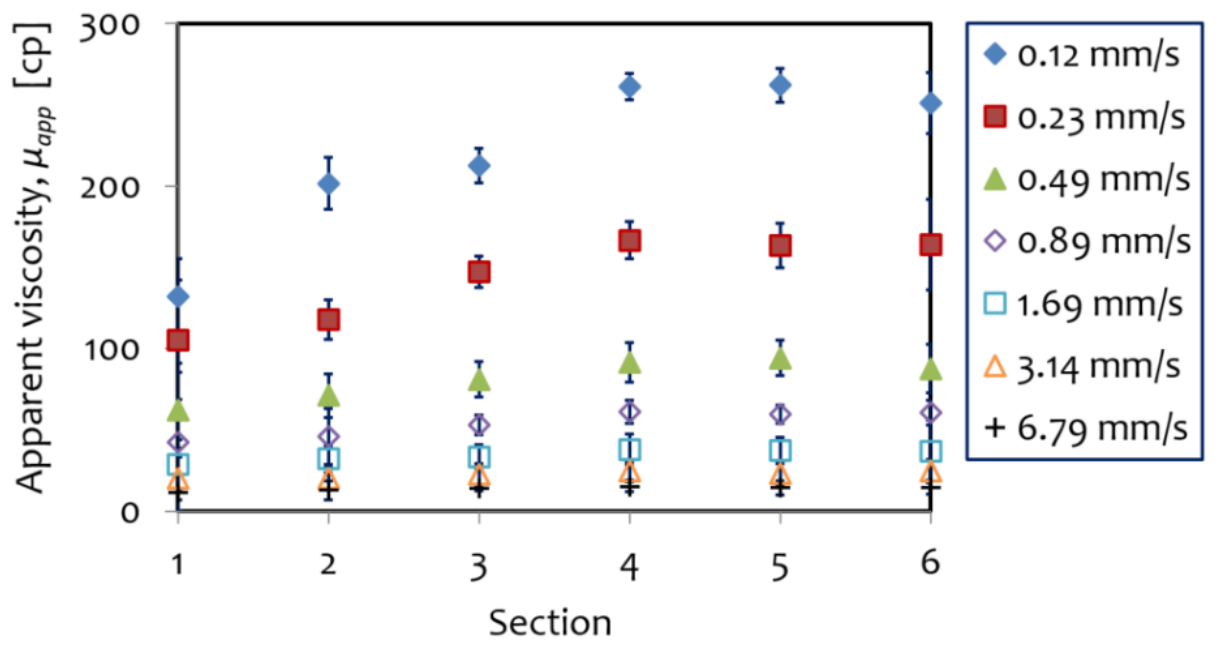

Figure 3 Apparent viscosity of foam in different sections of the fracture at different velocities

The apparent viscosity decreases as velocity increases, as shown in Figure 3, indicating that foam is a non-Newtonian fluid. Apparent viscosity increases along the fracture for all velocities, until in the last three sections where it reaches its maximum magnitude. We can conclude that pre-generated foam is refined by in-situ foam generation within the fracture. It enters a state of unchanging mobility as foam propagates down the fracture. In this study, lamella division is the key mechanism of in-situ foam generation within the fracture. Figure 4 displays a time-lapse picture of foam generation by lamella division. The highlighted bubbles represent events where moving lamellae are broken, thereby forming new bubbles.
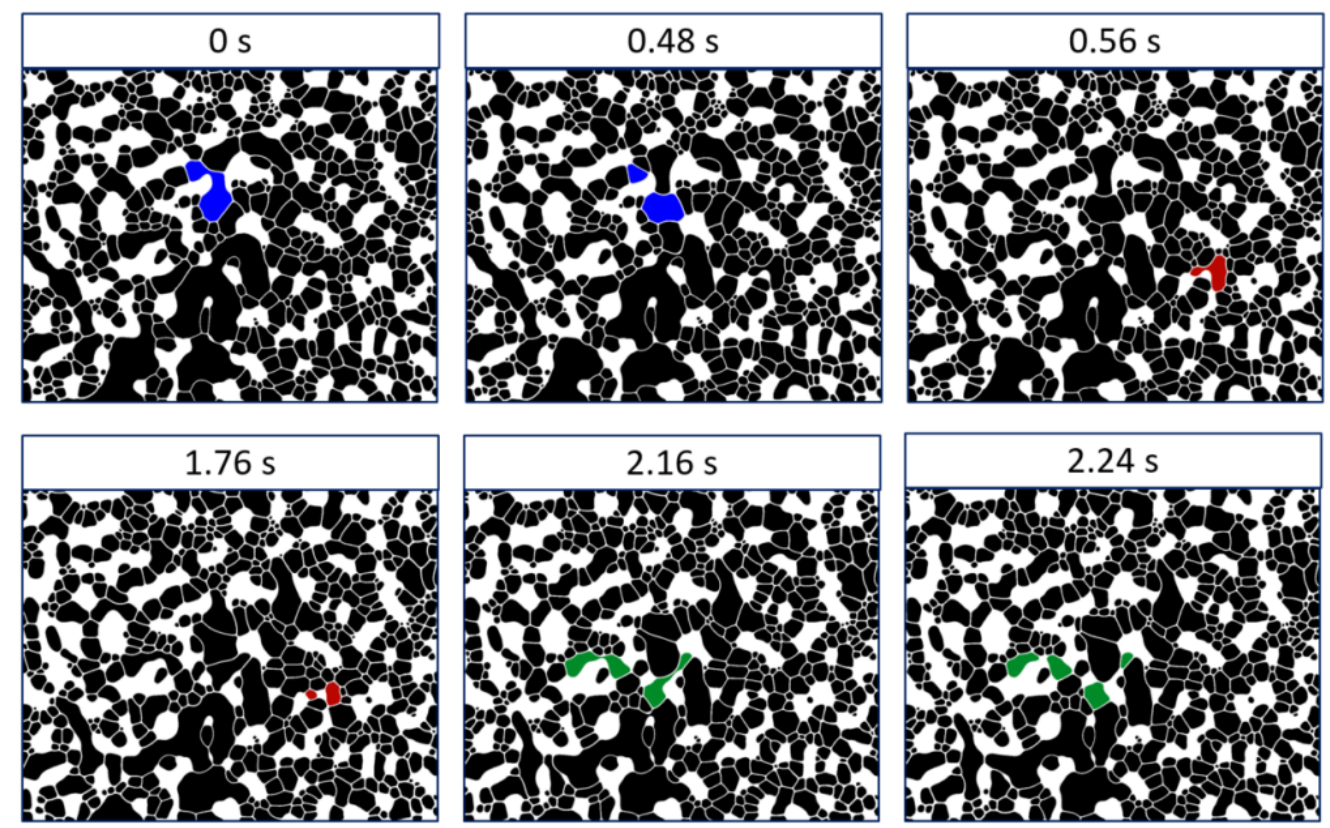

Figure 4 Foam generation by lamella division in Section 1. Foam is injected at $0.89 \mathrm{~mm} / \mathrm{s}$. Gas is shown in black, liquid in white. Image size: $1.95 \times 1.56 \mathrm{~cm}$ 
As shown in Figure 5, bubble texture becomes finer along the fracture as a result of in-situ foam generation. Figure 6 shows bubble density and bubble size of foam in six different sections. The statistics are given in Table 1. For foam injected at $0.89 \mathrm{~mm} / \mathrm{s}$, in the last three sections of our model fracture, the foam texture reaches a stable and constant state, with bubble density rising along the fracture to 509 per $\mathrm{cm}^{2}$, while the bubble size decreases to $0.139 \mathrm{~mm}^{2}$. The apparent viscosity also stays the same in the last three sections at $60 \mathrm{cp}$. In our model fracture, foam reaches local equilibrium (LE), where the rate of bubble generation equals the rate of destruction.
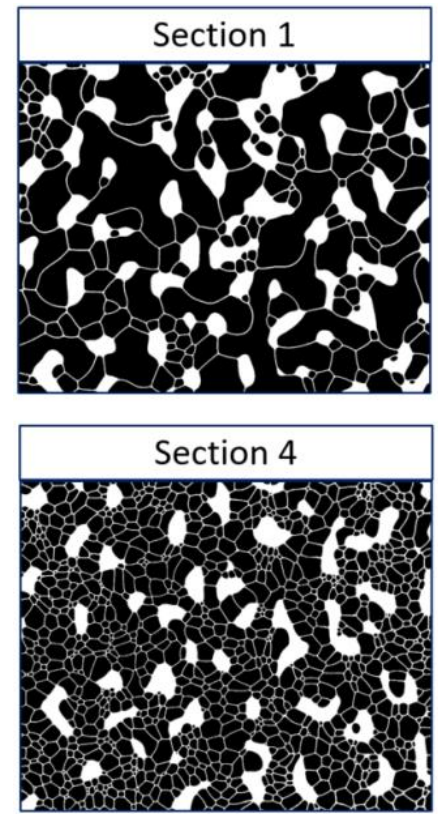
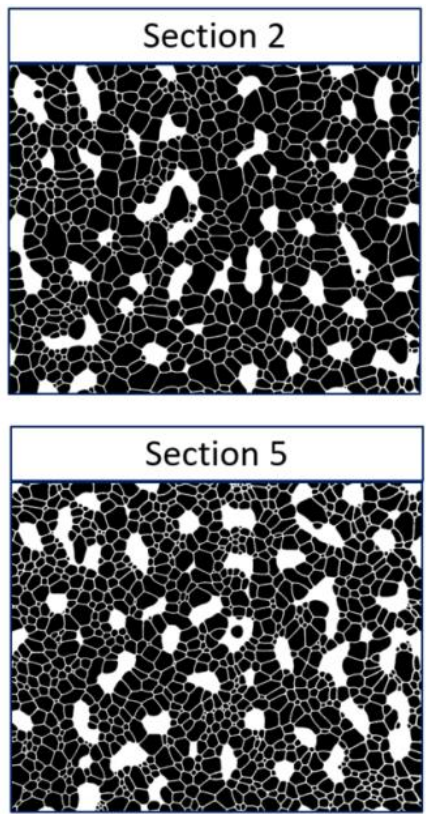
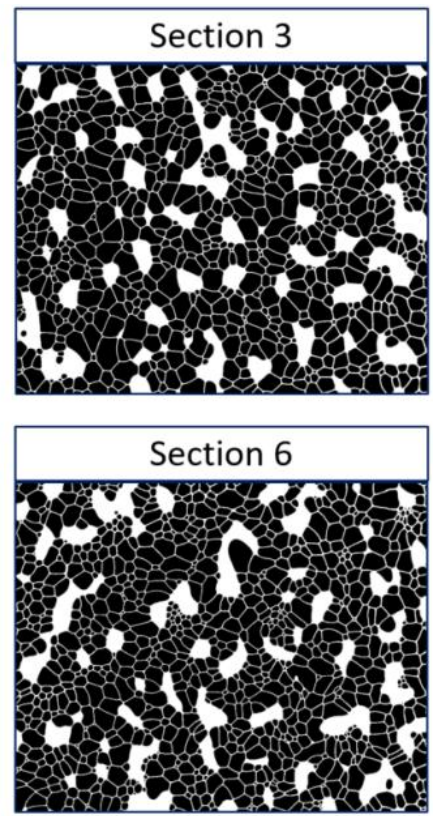

Figure 5 Evolution of foam texture. Foam is injected at $0.89 \mathrm{~mm} / \mathrm{s}$. Gas is shown in black, liquid in white. Image size: $1.57 \times 1.26 \mathrm{~cm}$

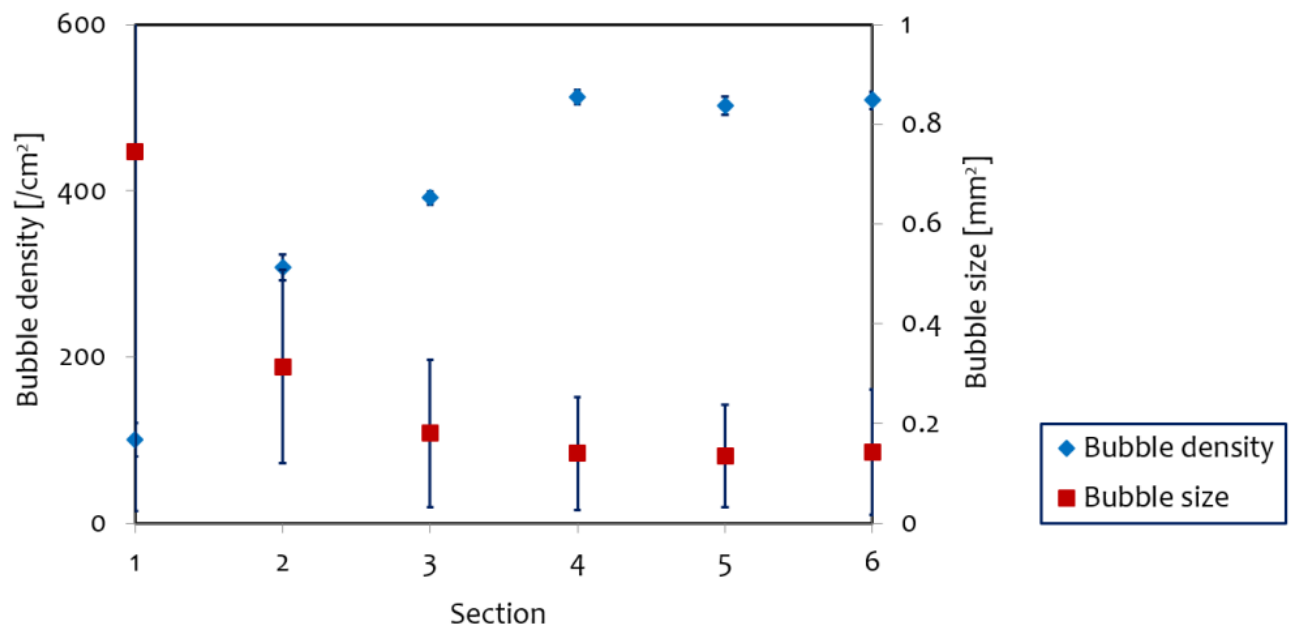

Figure 6 Bubble density and size in different sections of model fracture. Foam is injected at $0.89 \mathrm{~mm} / \mathrm{s}$ 
Section 1 Section 2 Section 3 Section 4 Section 5 Section 6

\begin{tabular}{lllllll}
\hline Bubble density [/1 $\mathbf{~ c m}^{2}$ image] & 100 & 308 & 391 & 513 & 502 & 509 \\
\hline Stdev. bubble density & 20 & 16 & 8 & 9 & 11 & 10 \\
\hline Bubble size $\left[\mathrm{mm}^{2}\right.$ ] & 0.745 & 0.314 & 0.180 & 0.140 & 0.135 & 0.142 \\
\hline Stdev. Bubble size & 0.721 & 0.193 & 0.148 & 0.113 & 0.102 & 0.125 \\
\hline $\begin{array}{l}\text { Polydispersivity index } \\
\text { [Stdev./average bubble size] }\end{array}$ & 0.97 & 0.62 & 0.82 & 0.81 & 0.76 & 0.88
\end{tabular}

Table 1 Bubble properties in different sections of model fracture. Foam is injected at $0.89 \mathrm{~mm} / \mathrm{s}$

\section{Effects of Gas Trapping on Foam Mobility}

Foam experiments at various interstitial velocities have been performed to study gas trapping and its effects on foam mobility. Figure 7 shows that the bubble texture of LE foam and total interstitial velocity are closely related. As velocity increases, bubble density rises and bubble size decreases. Statistics are shown in Table 2.

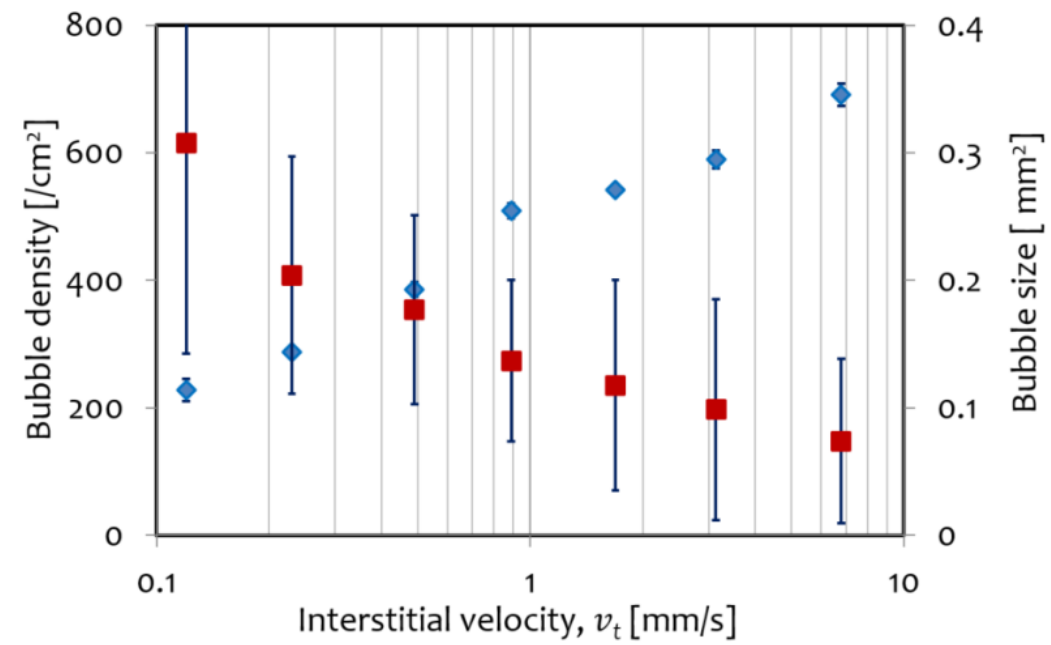

Bubble density

Bubble size

Figure 7 Bubble density and bubble size of LE foam at different velocities

\begin{tabular}{llllllll} 
Total Interstitial velocity [mm/s] & $\mathbf{0 . 1 2}$ & $\mathbf{0 . 2 3}$ & $\mathbf{0 . 4 9}$ & $\mathbf{0 . 8 9}$ & $\mathbf{1 . 6 9}$ & $\mathbf{3 . 1 4}$ & $\mathbf{6 . 7 9}$ \\
\hline Bubble density [/1 $\mathbf{~ c m}^{\mathbf{2}}$ image] & 228 & 288 & 386 & 509 & 542 & 590 & 691 \\
\hline Stdev. bubble density & 18 & 9 & 11 & 12 & 8 & 14 & 18 \\
\hline Bubble size [ $\mathbf{m m}^{2}$ ] & 0.308 & 0.204 & 0.177 & 0.137 & 0.118 & 0.099 & 0.074 \\
\hline Stdev. Bubble size & 0.165 & 0.093 & 0.074 & 0.063 & 0.082 & 0.086 & 0.064 \\
\hline $\begin{array}{l}\text { Polydispersivity index } \\
\text { [Stdev./average bubble size] }\end{array}$ & 0.54 & 0.46 & 0.42 & 0.46 & 0.70 & 0.88 & 0.87
\end{tabular}

Table 2 Bubble properties of LE foam at different velocities

There are more foam bubbles generated by lamella division at higher velocities. The bubble density of the LE foam at $6.79 \mathrm{~mm} / \mathrm{s}$ increases by a factor of 3 compared to $0.12 \mathrm{~mm} / \mathrm{s}$, and the bubble size decreases by a factor of 4 .

The fraction of trapped gas and the pressure gradient in the LE foam at various velocities are shown in Figure 8. As velocities increases, the trapped-gas fraction decreases. The inverse relation of gas trapping 
to velocity, in spite of smaller bubble size, is ascribed to the increase in pressure gradient at higher velocities. At higher velocities, the increasing viscous forces dominate the capillary forces, and more gas bubbles become mobile. Consequently, the proportion of gas that is trapped in the fracture decreases.
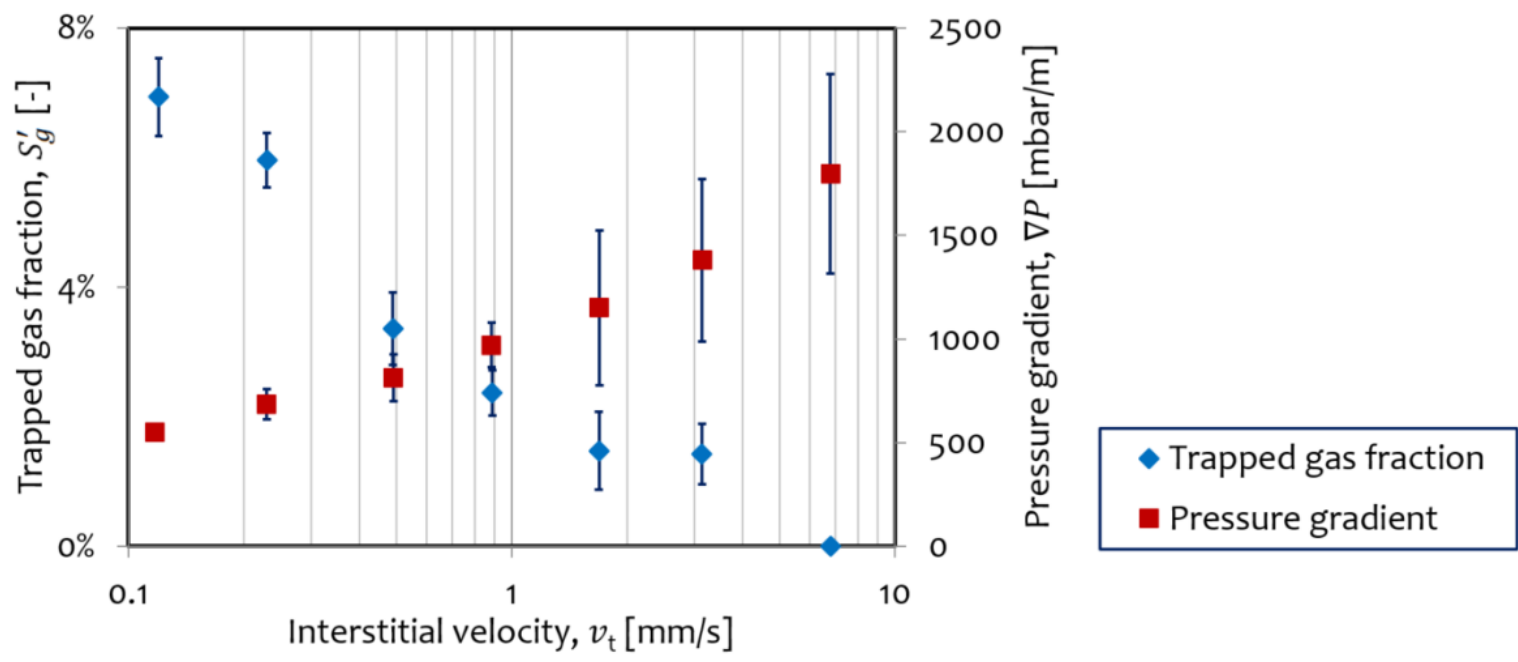

Figure 8 Fraction of trapped gas and pressure gradient of LE foam at different velocities

The fraction of trapped gas discovered in our model fracture is very small compared to previous studies in geological porous media and microfluidic models. As shown in Figure 9, the fraction of trapped gas is $6.9 \%$ at $0.12 \mathrm{~mm} / \mathrm{s}$. There is no gas trapping as the injection velocity rises up to $6.79 \mathrm{~mm} / \mathrm{s}$.
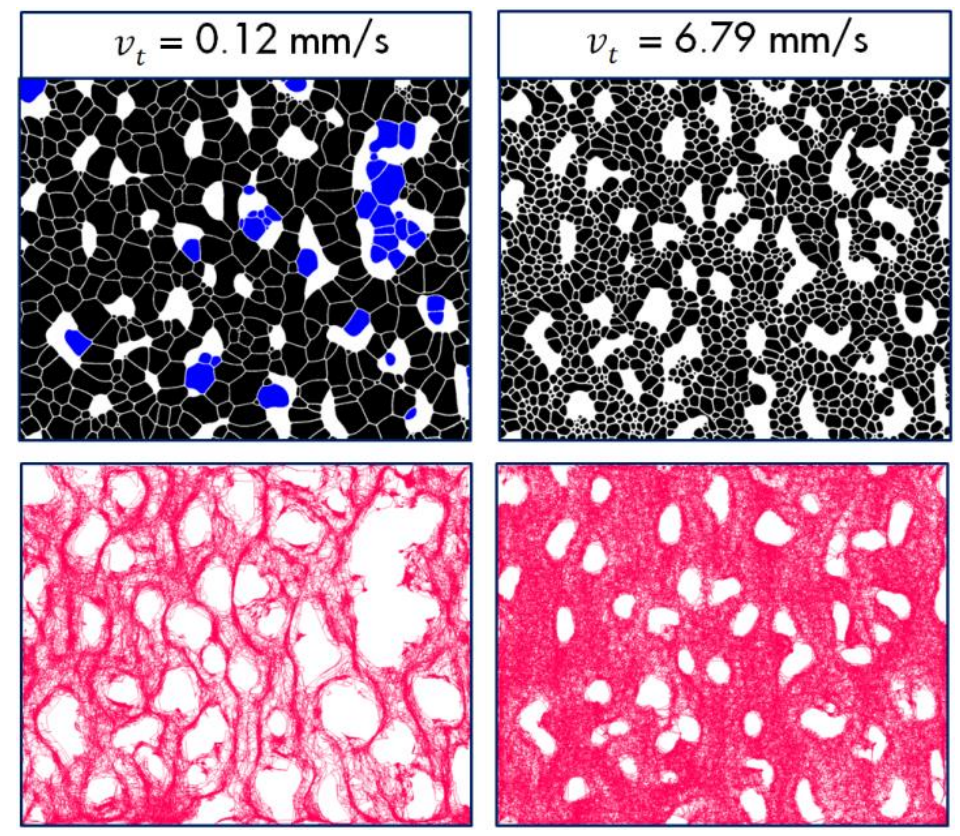

Figure 9 Images of foam texture (top) and streamlines of foam flow (bottom) at two different velocities: left, at $0.12 \mathrm{~mm} / \mathrm{s}$, streamlines of bubble flow based on 12 minutes of injection; right, at $6.79 \mathrm{~mm} / \mathrm{s}$, streamlines of bubble flow based on 5 minutes of injection. In the top images, flowing gas is portrayed in black, trapped gas in blue, and liquid in white. In the bottom images, streamlines are in red. Image size: $1.57 \times 1.26 \mathrm{~cm}$

Figure 10 shows foam apparent viscosity as a function of velocities. Foam in our model fracture displays a strongly shear-thinning rheology, with a power-law exponent (Bird et al. 2002) of 0.32. Despite stronger refinement of foam texture at higher velocities, apparent viscosity decreases by a factor of 17 , 
from $258 \mathrm{cp}$ at $0.12 \mathrm{~mm} / \mathrm{s}$ to $15 \mathrm{cp}$ at $6.79 \mathrm{~mm} / \mathrm{s}$, while the proportion of gas which is flowing increases from $93 \%$ to $100 \%$. At this high flowing-gas fraction, it is challenging to argue that gas trapping plays a crucial role in the increase of foam mobility.

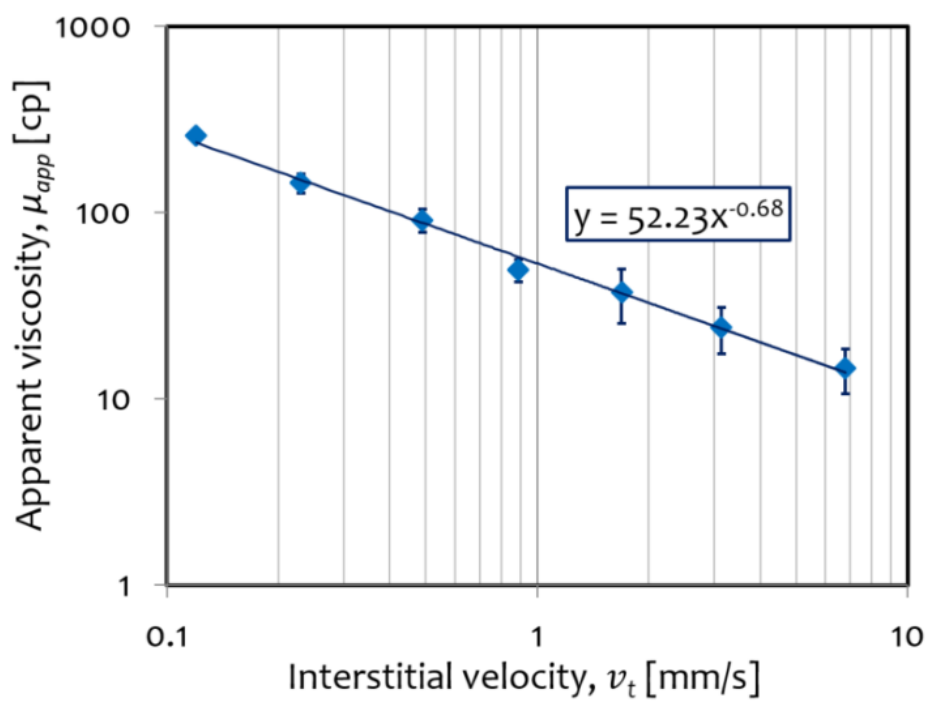

Figure 10 Apparent viscosity of LE foam at different velocities

\section{Conclusions}

In this experimental study, we built a 1-meter-long and 15-centimeter-wide glass model fracture. To investigate gas trapping in foam and how it affects the mobility of foam in fractures, a series of foam experiments at a fixed foam quality of 0.9 and a varying total interstitial velocity have been conducted in the model. Before being injected inside the model fracture, foam was pre-generated through a mixing tee. For each experiment at a specific total interstitial velocity, the pre-generated foam was further refined in the fracture, mainly by lamella division. Foam texture was finer and the apparent viscosity of foam increased along the model fracture until the last three sections, where the foam had the same properties. Within our model fracture, the local equilibrium of foam has been achieved, where bubble generation rate is the same as bubble destruction rate. With increasing velocities, foam texture became finer; there was more foam generation in-situ at a larger pressure gradient. Foam flow showed a strong shear-thinning behavior in our study. We found that the trapped-gas fraction decreased as velocity and pressure gradient increased. Notably, the trapped-gas fractions found in our model fracture were less than $7 \%$ in all cases. At the extreme, all gas was flowing and there was no gas trapped inside the fracture when the velocity increased to $6.8 \mathrm{~mm} / \mathrm{s}$. The fractions of trapped gas are much less than what has been reported for either geological porous media or microfluidic models. At such low trapped-gas fractions, the effect of gas trapping on foam mobility is relatively insignificant.

\section{References}

AlQuaimi, B.I. and Rossen, W.R. [2019] Study of foam generation and propagation in fully characterized physical-model fracture. Journal of Petroleum Science and Engineering, 175, 1169-1181.

Bird, R., Stewart, W., Lightfoot, E. [2002] Transport Phenomena 2nd edition John Wiley and Sons. New York.

Conn, C.A. [2015] The characterization and visualization of multi-phase systems using microfluidic devices (Doctoral dissertation). 
Fernø, M.A., Gauteplass, J., Pancharoen, M., Haugen, Å., Graue, A., Kovscek, A.R., Hirasaki, G. [2016] Experimental study of foam generation, sweep efficiency, and flow in a fracture network. SPE Journal, 21(04), 1-140.

Friedmann, F., Chen, W.H., Gauglitz, P.A. [1991] Experimental and simulation study of hightemperature foam displacement in porous media. SPE reservoir engineering, $\mathbf{6}(01), 37-45$.

Hirasaki, G.J., Miller, C.A., Szafranski, R., Lawson, J.B., Akiya, N. [1997] Surfactant/foam process for aquifer remediation. In International symposium on oilfield chemistry. SPE 37257-MS.

Jones, S.A., Getrouw, N., Vincent-Bonnieu, S. [2018] Foam flow in a model porous medium: II. The effect of trapped gas. Soft matter, 14(18), 3497-3503.

Kil, R.A., Nguyen, Q.P., Rossen, W.R. [2011] Determining trapped gas in foam from computedtomography images. SPE Journal, 16(01), 24-34.

Kim, J., Dong, Y., Rossen, W.R. [2005] Steady-state flow behavior of CO2 foam. SPE Journal, 10(04), 405-415.

Kovscek, A.R., Radke, C.J. [1994] Fundamentals of foam transport in porous media, in: L. L. Schramm (ed), Foams in the Petroleum Industry, Washington, D.C., Amer. Chem. Soc. 242, 115-163.

Kovscek, A.R., Tretheway, D.C., Persoff, P., Radke, C.J. [1995] Foam flow through a transparent rough-walled rock fracture. Journal of Petroleum Science and Engineering, 13(2), 75-86.

Lake, L.W., Johns, R.T., Rossen W.R., Pope, G.A. [2014] Fundamentals of Enhanced Oil Recovery, Society of Petroleum Engineers, Richardson, TX.

Marchalot, J., Lambert, J., Cantat, I., Tabeling, P., Jullien, M.C. [2008] 2D foam coarsening in a microfluidic system. EPL (Europhysics Letters), 83(6), 64006.

Nguyen, Q.P., Rossen, W.R., Zitha, P.L., Currie, P.K. [2009] Determination of gas trapping with foam using X-ray computed tomography and effluent analysis. SPE Journal, 14(02), 222-236.

Portois, C., Essouayed, E., Annable, M.D., Guiserix, N., Joubert, A., Atteia, O. [2018] Field demonstration of foam injection to confine a chlorinated solvent source zone. Journal of contaminant hydrology, 214, 16-23.

Radke, C.J., Gillis, J.V. [1990] A dual tracer technique for determining trapped gas saturation during steady foam flow in porous media. Paper SPE 20519 presented at the 65th Annual Technical Conference and Exhibition, New Orleans. In Tech. Conf. Exhib., New Orleans, LA.

Rossen, W.R. [1996] Foams in enhanced oil recovery. Foams: theory, measurements and applications, 57, 413-464.

Tang, G.Q., Kovscek, A.R. [2006] Trapped gas fraction during steady-state foam flow. Transport in porous media, $\mathbf{6 5}(2), 287-307$.

Thompson, K.E., Gdanski, R.D. [1993] Laboratory study provides guidelines for diverting acid with foam. SPE Production \& Facilities, 8(04), 285-290.

Witherspoon, P.A., Wang, J.S., Iwai, K., Gale, J.E. [1980] Validity of cubic law for fluid flow in a deformable rock fracture. Water resources research, 16(6), 1016-1024. 